\title{
Ending systemic racism in medicine
}

\author{
Black Lives Matter - we pledge to do our part to eliminate racism in science and medicine.
}

G eorge Floyd died on 25 May 2020 in Minneapolis, Minnesota. A Black man, he was killed by a white police officer who knelt on his neck for 8 minutes and 46 seconds and ignored his calls to be allowed to breathe - all of it caught on camera. The police officer did not object to being caught on camera, in an act of defiance that embodies the extent to which police brutality against Black people has gone unaccounted for in the USA and elsewhere. Like Breonna Taylor, Ahmaud Arbery, Amadou Diallo and too many more Black people before Floyd, his life was taken without jury, defense or cause.

The weeks that followed his death have seen a widespread reckoning of systemic racism nationally and internationally, and a broader assessment of racism and responsibility for it within every sector of society. In the USA, where state-sanctioned racial segregation was outlawed in the 1960 s, de facto segregation is still the reality - Black communities still are denied opportunities, access to health, education, jobs, housing and security, and the right to live a happy and fulfilling life. We at Nature Medicine believe that the responsibility for fixing these disparities lies with those who created them in the first place - all of us who are not Black and who failed to stand up and speak out against anti-Black racism in whatever capacity we could.

In acknowledging our role as part of a system that enables the perpetration of anti-Black racism, we hope to leverage our position as a trusted source of information in the translational and clinical sciences to actively pursue and amplify important discussions about racial disparities in the context of health and medicine. On our editorial team, not all of us are white, but none of us are Black, so we cannot speak of the challenges of being Black in an anti-Black racist society. Because of that, we pledge to continuously educate ourselves about our own privilege and the responsibility that comes with it, and to seek out feedback from the Black members of the scientific community to ensure that we implement solutions that best meet their needs. We recognize that our role as editors allows us to curate and amplify information, and therefore that our responsibility toward eliminating systemic racism extends to what we decide to put in our pages.

Systemic racism means that there are unique challenges for Black people and people of color in being accepted into universities, pursuing higher degrees, becoming professors, being consulted for peer review and evaluating grant applications. And one only has to read the disheartening accounts shared with the \#BlackinIvory hashtag to realize that being a Black scientist is made considerably more difficult by microagressions carried out, often unwittingly, by their colleagues. We commit to making Nature Medicine more inclusive. We pledge to develop an agenda to increase the representation of Black authors - and of other under-represented subsets of our readership - in our pages, whether through commissioned content, by increasing the reach of our outreach activities, by the diversification of our referee pool or by identifying and fostering research that addresses the current racial disparities in science and medicine.

We also pledge to be watchful of research that may perpetuate and enable racism. There are numerous records of abuses that have been done in the name of the advancement of biomedical sciences. HeLa cells were originally taken from Henrietta Lacks' body, herself African-American, without her consent, which violated her human right to have ownership of her body. In the Tuskegee experiments, Black men who had syphilis were not informed of their status and did not receive treatment. Sims vaginal speculum was developed through horrific surgeries performed on enslaved Black women without anesthesia.
Such biases continue to affect mainstream medical research today. Only recently, healthcare algorithms were found to discriminate against people of color. Facial-recognition systems, which are being adopted broadly by law enforcement and border control, have proved to consistently fail to match Asian and African-American people to their photos. Angela Saini, who conducted an investigation of the history of race sciences in her book Superior, has warned medical researchers that if they do not have a clear understanding of what they mean when they measure race in clinical trials, they could be perpetuating biases in medical sciences. Black Americans are still under-represented in clinical trials, which is sometimes blamed on their fear of participating in medical research. Harriet A. Washington, author of Medical Apartheid, says this fear, which is often dismissed as paranoia, should be taken as a legitimate concern based on 400 years of abuse. Moreover, systemic racism disproportionately affects the health of Black people. This has been brought into sharp focus by the COVID19 pandemic, during which Black people are dying disproportionately in the USA and elsewhere. Systemic racism is also a public-health emergency, and actively combating its effects on medical research must be made a priority.

It is with the mindset that no one single effort can eradicate racism, but that every step we take toward that goal matters, that we pledge to continue to talk and write about systemic racism, until there is no more racism. We kindly ask our readers to hold us accountable for our progress. George Floyd's tragic killing unleashed the potential for real societal change. It is time to realize that potential.

Published online: 10 July 2020 https://doi.org/10.1038/s41591-020-0993-2 